\title{
CORRECTION
}

\section{Correction to: Twist-minimal trace formula for holomorphic cusp forms}

\author{
Kieran Child (D)
}

${ }^{*}$ Correspondence:

kieran.child@bristol.ac.uk

University of Bristol, Beacon

House, Queens Road, Bristol BS8

IQU, UK

The original article can be found

online at https://doi.org/10.

1007/s40993-021-00302-9

\section{Correction to: Res. Number Theory \\ https://doi.org/10.1007/s40993-021-00302-9}

\section{Errata}

(1) On page 3, equation 2.5, the congruence subgroup $\Gamma_{0}(N)$ should be defined as the following subgroup of $\mathrm{SL}_{2}(\mathbb{Z})$ :

$$
\Gamma_{0}(N)=\left\{\left(\begin{array}{ll}
a & b \\
c & d
\end{array}\right) \in \mathrm{SL}_{2}(\mathbb{Z}): N \mid c\right\} .
$$

(2) At the top of page 4, the second condition for a modular form should state that $\left.f\right|_{k} \gamma(z)$ is bounded as $\Im(z) \rightarrow z$ for all $\gamma \in \mathrm{SL}_{2}(\mathbb{Z})$.

(3) On page 4, a cusp form is a modular form for which $\left.f\right|_{k} \gamma(z) \rightarrow 0$ as $\Im(z) \rightarrow \infty$ for all $\gamma \in \mathrm{SL}_{2}(\mathbb{Z})$.

The original article can be found online at https://doi.org/10.1007/s40993-021-00302-9.

Published online: 20 January 2022

\section{Publisher's Note}

Springer Nature remains neutral with regard to jurisdictional claims in published maps and institutional affiliations. 